\title{
PENGARUH PERSEPSI KARYAWAN TENTANG KEADILAN KOMPENSASI TERHADAP KEPUASAN KERJA DI PERUSAHAAN X
}

\author{
Wahyudhi Sutrisno \\ Jurusan Teknik Industri, Fakultas Teknologi Industri, Universitas Islam Indonesia, \\ Jalan Kaliurang Km. 14,5 Yogyakarta, Sleman, 55584
}

\begin{abstract}
This research aims to know whether employees perception to compensation justice which is accepted affecting the level of employee's job satisfaction. Research data obtained from primary data and secondary data. Primary data obtained by giving questionnaire to respondent. Secondary data consist of history of the company, company's profile, organization chart, total of employees, and applied compensation system. Data analysis using the analysis of linear regression and correlation analysis. result of this research shows that there is significantly influence between employees perception to compensation justice with job satisfaction. And there is closer relationship between perception variable about justice of compensation system with job satisfaction.
\end{abstract}

Keywords: Compensation Justice, Job Satisfaction, Employee's Perception.

\section{PENDAHULUAN}

Perusahaan atau organisasi saat ini dituntut untuk mempunyai keunggulan bersaing baik dalam hal kualitas produk, servis, biaya maupun sumber daya manusia yang profesional. Sumber Daya Manusia merupakan kemampuan terpadu dari daya pikir dan daya fisik yang dimiliki individu, dimana pelaku dan sifatnya dilakukan oleh keturunan dan lingkungannya, sedangkan prestasi kerjanya dimotivasi oleh keinginan untuk memenuhi kepuasannya (Hasibuan, 2013). Manajemen Sumber Daya Manusia menurut Marwansyah (2010), dapat diartikan sebagai pendayagunaan sumber daya manusia di dalam organisasi, yang dilakukan melalui fungsi-fungsi perencanaan sumber daya manusia, rekruitmen dan seleksi, pengembangan sumber daya manusia, perencanaan dan pengembangan karir, pemberian kompensasi dan kesejahteraan, keselamatan dan kesehatan kerja, dan hubungan industrial.

Pada perusahaan $\mathrm{X}$ yang bergerak dibidang jasa, maka karyawan memegang peranan kunci, sebab proses "konsumsi" terjadi bersamaan dengan proses "produksi". Karyawan, terutama yang terlibat langsung dengan konsumen sebenarnya merupakan bagian dari jasa yang dijual. Karyawan akan dapat memberikan servis yang baik kepada konsumen apabila karyawan merasa puas terhadap pekerjaannya. Karyawan yang puas terhadap pekerjaannya, maka produktivitas kerja dan motivasi kerja karyawan tersebut juga akan meningkat. Tujuan penelitian ini adalah untuk mengetahui apakah persepsi karyawan terhadap keadilan kompensasi yang diterima mempengaruhi tingkat kepuasan kerja karyawan.

\section{KAJIAN LITERATUR}

\section{1 Kompensasi}

Milkovich (2002) mendefinisikan kompensasi sebagai semua bentuk financial return, tangible services dan benefit yang diterima karyawan sebagai bagian dari hubungan kerja antara perusahaan dan karyawan. Menurut Hasibuan (2013), kompensasi merupakan suatu cara perusahaan untuk meningkatkan motivasi dan kepuasan kerja karyawan. Kompensasi penting bagi karyawan sebagai individu 
karena besarnya kompensasi mencerminkan ukuran nilai karya mereka diantara karyawan itu sendiri, keluarga dan masyarakat.

\section{2 Persepsi}

Persepsi merupakan proses dari seseorang dalam memahami lingkungannya yang melibatkan pengorganisasian dan penafsiran sebagai rangsangan dalam suatu pengalaman psikologis. Persepsi membantu individu dalam memilih, mengatur, menyimpan dan menginterpretasikan rangsangan menjadi gambaran dunia yang utuh dan berarti. Hubungan antara keadilan dan kepuasan terhadap kompensasi dijelaskan dalam teori keadilan (equity theory) yang menyatakan bahwa karyawan membandingkan upaya dan imbalan mereka dengan karyawan lain dalam situasi kerja yang sama (Gibson, 2000).

\section{3 Kepuasan Kerja}

Kepuasan kerja menurut Gibson (2000) yaitu sikap yang ditunjukkan oleh individu mengenai pekerjaannya, yang merupakan hasil dari persepsinya mengenai lingkungan kerja. Lima dimensi kerja yang dianggap berhubungan dengan kepuasan kerja karyawan yaitu:

1. Pay. Jumlah yang diterima dan dirasakan adil.

2. Job. Pekerjaan yang diberikan semakin menarik dan memberikan kesempatan bagi karyawan untuk belajar dan meningkatnya tanggung jawab.

3. Promotion Oportunities. Peluang kenaikan pangkat.

4. Supervisor. Kemampuan supervisor dalam menunjukkan kepeduliannya terhadap karyawan.

5. Co-worker. Rekan kerja yang suportif dan kompeten.

\section{4 Keadilan Kompensasi}

Milkovich (2002) menyebutkan keadilan (fairness) merupakan sasaran utama sistem kompensasi. Menurut Simamora (2004), keadilan (equity) adalah keseimbangan antara masukan yang dibawa masuk oleh individu ke dalam sebuah pekerjaan dengan hasil yang diperolehnya dari pekerjaan tersebut. Masukan karyawan meliputi pengalaman, pendidikan, keahlian khusus, upaya dan waktu kerja. Keluarannya meliputi gaji, tunjangan-tunjangan, pencapaian, pengakuan dan imbalan lainnya. Perancangan dan pelaksanaan sistem kompensasi haruslah memastikan bahwa terdapat keadilan eksternal, internal, dan individu melalui perancangan dan penerapan struktur gaji yang efektif dan tingkat gaji yang tepat. Keadilan eksternal (external equity) diartikan sebagai kompensasi yang wajar dan berlaku untuk pekerjaan-pekerjaan serupa di pasar tenaga kerja eksternal. Keadilan eksternal dinilai dengan membandingkan pekerjaan serupa diantara perusahaan-perusahaan yang dapat dibandingkan. Dua kondisi mestilah dipenuhi: (1) pekerjaan yang sedang diperbandingkan mestilah sama atau hampir sama, dan (2) organisasi yang disurvai mestilah serupa dalam ukuran, misi dan sektornya. Tingkat kompensasi eksternal dipengaruhi oleh: (1) faktor-faktor pasar tenaga kerja, seperti sifat permintaan dan suplai tenaga kerja; (2) faktor-faktor pasar dari produk, seperti tingkat kompetisi, tingkat permintaan produk, karakteristik industri dan faktor-faktor lainnya yang mempengaruhi kesehatan industri dan kemampuannya menggaji; (3) harga modal dan tingkat terhadap harga modal tersebut dapat disubstitusikan untuk tenaga kerja dalam proses yang produktif (Simamora, 2004). Menurut Simamora (2004), keadilan internal (internal equity) diartikan sebagai tingkat kompensasi yang pantas dengan nilai pekerjaan internal bagi pekerjaan. Keadilan internal adalah fungsi dari status relatif sebuah pekerjaan didalam perusahaan, nilai ekonomi hasil pekerjaan atau status sosial sebuah pekerjaan. Keadilan ini berhubungan dengan variasi kompensasi diantara pekerjaan-pekerjaan yang berbeda dalam suatu perusahaan. Keadilan individu (individual equity) berarti bahwa individu- 
individu merasa bahwa mereka diperlakukan secara adil dibandingkan dengan rekan sekerja mereka.

\section{METODOLOGI PENELITIAN}

\subsection{Pengumpulan Data}

1. Data primer, yaitu data yang diperoleh secara langsung dari sumber obyek penelitian. Data primer dari penelitian ini diperoleh langsung dari karyawan perusahaan $\mathrm{X}$ dengan menggunakan kuisioner. Kuisioner menggunakan skala Likert yang dimodifikasi dari lima pilihan jawaban menjadi empat pilihan jawaban dengan menghilangkan pilihan jawaban ragu-ragu/netral. Tujuannya adalah untuk mengurangi akibat yang tidak diinginkan dengan alasan (Hadi,2004) :

a. Jawaban ragu-ragu diartikan belum dapat memutuskan.

b. Jawaban yang tersedia di tengah akan menimbulkan kecenderungan menjawab ke tengah (central tendency effect), terutama bila masih ragu-ragu dalam menentukan pilihan.

c. Tidak tersedianya jawaban di tengah secara langsung membuat subyek harus menentukan pendapat dengan lebih pasti ke arah setuju atau tidak setuju.

2. Data sekunder, yaitu data yang diperoleh dari perusahaan $\mathrm{X}$ yang meliputi sejarah perusahaan, gambaran umum perusahaan, struktur organisasi, jumlah karyawan, dan sistem kompensasi yang diterapkan.

\section{2 Definisi Operasional dan Pengukuran Variabel}

Terdapat dua variabel yang digunakan dalam penelitian ini yaitu variabel persepsi karyawan terhadap keadilan kompensasi dan kepuasan kerja. Persepsi karyawan terhadap keadilan kompensasi merupakan variabel independen dan variabel kepuasan kerja merupakan variabel dependen.
1. Variabel persepsi karyawan terhadap sistem kompensasi didasarkan pada keadilan kompensasi yang meliputi :

a. Keadilan eksternal, yaitu kompensasi yang pantas sesuai dengan kompensasi yang berlaku di pasar eksternal. Keadilan ini dinilai dengan membandingkan kompensasi pada pekerjaan serupa di antara organisasi yang sejenis. Pernyataan yang berkaitan dengan keadilan eksternal meliputi dimensi bentuk dan jumlah.

b. Keadilan internal, yaitu kompensasi yang diberikan sesuai dengan nilai pekerjaan internal bagi perusahaan. Keadilan ini dinilai dengan membandingkan kompensasi pada berbagai pekerjaan yang berbeda di dalam perusahaan. Pernyataan yang berkaitan dengan keadilan internal meliputi dimensi bentuk, jumlah administrasi dan pelayanan.

c. Keadilan individu, yaitu keadilan dalam kompensasi dimana seseorang menilai keadilan dengan membandingkan apa yang diperolehnya dengan apa yang diperoleh rekan kerjanya. Pernyataan yang berkaitan dengan keadilan individu meliputi dimensi bentuk, jumlah, administrasi dan pelayanan.

2. Variabel Kepuasan Kerja meliputi :

a. Pendapatan (Pay). meliputi besar gaji dan tunjangan.

b. Pekerjaan (Job). Meliputi beban kerja, kesesuaian minat, variasi pekerjaan, keamanan kerja, kebebasan bertindak, sarana penunjang kerja dan lingkungan kerja.

c. Promosi dan pengembangan karir (Promotion Oportunities). Meliputi kesempatan pengembangan diri dan keadilan dalam sistem promosi.

d. Atasan (Supervisor). Meliputi dukungan dan perhatian atasan, keterbukaan atasan, pengawasan atasan. 
e. Rekan kerja (Co-worker). Meliputi komunikasi dan keterbukaan, persaingan, kebersamaan dan dukungan kelompok, penyelesaian masalah dan umpan balik.

\subsection{Metode Analisis Data}

Data dianalisa dengan menggunakan Analisis Regresi Linear untuk menunjukkan sifat hubungan antara variabel independen dan variabel dependen (Nawari, 2010). Persamaan regresi:

$\mathrm{Y}^{\prime}=\mathrm{a}+\mathrm{Bx}$

dimana :

$\mathrm{Y}^{\prime}=$ Kepuasan Kerja.

$\mathrm{a}=$ Intercep.

$\mathrm{B}=$ Koefisien Regresi Variabel Persepsi terhadap Keadilan Kompensasi.

$\mathrm{x}=$ Variabel Persepsi Terhadap Keadilan Kompensasi.

Analisis korelasi digunakan untuk menjelaskan besarnya tingkat hubungan antara variabel persepsi tentang keadilan kompensasi dengan kepuasan kerja karyawan. Perhitungan koefisien korelasi dengan menggunakan teknik Pearson's Product Moment dengan dengan rumus sebagai berikut :

$r=\frac{N \sum X Y-\left(\sum X\right)\left(\sum Y\right)}{\sqrt{\left\{N \sum X^{2}-(X)^{2}\right\}\left\{N \sum Y^{2}-\left(\sum Y\right)^{2}\right\}}}$

dimana:

$\mathrm{Y}=$ Persepsi Terhadap Kepuasan Kerja.

$\mathrm{X}=$ Persepsi Terhadap Keadilan Sistem

Kompensasi.

$\mathrm{N}=$ Jumlah Item (pernyataan).

\section{HASIL DAN PEMBAHASAN}

\subsection{Keadilan Kompensasi}

Hasil tabulasi tentang keadilan kompensasi dapat dilihat pada tabel-tabel berikut ini :
Tabel 1. Keadilan Eksternal

\begin{tabular}{ccc}
\hline & Frekuensi & Persen $(\%)$ \\
\hline SS & 33 & 16,9 \\
S & 91 & 46,7 \\
TS & 69 & 35,4 \\
STS & 2 & 1,0 \\
Total & 195 & 100,0 \\
\hline
\end{tabular}

Tabel 1 menunjukkan bahwa karyawan mempunyai persepsi perusahaan telah menerapkan keadilan eksternal dalam sistem kompensasi perusahaan.

Tabel 2. Keadilan Internal

\begin{tabular}{ccc}
\hline & Frekuensi & Persen $(\%)$ \\
\hline SS & 38 & 19,5 \\
S & 89 & 45,6 \\
TS & 65 & 33,3 \\
STS & 3 & 1,5 \\
Total & 195 & 100,0 \\
\hline
\end{tabular}

Tabel 2 menunjukkan bahwa karyawan mempunyai persepsi perusahaan telah menerapkan keadilan internal dalam sistem kompensasi perusahaan.

Tabel 3. Keadilan Individu

\begin{tabular}{ccc}
\hline & Frekuensi & Persen $(\%)$ \\
\hline SS & 29 & 14,9 \\
S & 92 & 47,2 \\
TS & 71 & 36,4 \\
STS & 3 & 1,5 \\
Total & 195 & 100,0 \\
\hline
\end{tabular}

Tabel 3 menunjukkan bahwa karyawan mempunyai persepsi perusahaan telah menerapkan keadilan individu dalam sistem kompensasi perusahaan.

\subsection{Kepuasan Kerja}

Hasil tabulasi tentang kepuasan kerja dapat dilihat pada tabel-tabel berikut ini :

Tabel 4. Faktor Pekerjaan

\begin{tabular}{ccc}
\hline & Frekuensi & Persen $(\%)$ \\
\hline SS & 103 & 52,8 \\
S & 68 & 34,9 \\
TS & 24 & 12,3 \\
STS & 0 & 0,0 \\
Total & 195 & 100,0 \\
\hline
\end{tabular}


Tabel 4 menunjukkan bahwa karyawan telah merasakan kepuasan kerja yang berhubungan dengan faktor pekerjaan.

Tabel 5. Faktor Atasan

\begin{tabular}{ccc}
\hline & Frekuensi & Persen $(\%)$ \\
\hline SS & 133 & 68,2 \\
S & 52 & 26,7 \\
TS & 9 & 4,6 \\
STS & 1 & 0,5 \\
Total & 195 & 100,0 \\
\hline
\end{tabular}

Tabel 5 menunjukkan bahwa karyawan telah merasakan kepuasan kerja yang berhubungan dengan faktor atasan.

Tabel 6. Faktor Promosi

\begin{tabular}{ccc}
\hline & Frekuensi & Persen $(\%)$ \\
\hline SS & 154 & 79,0 \\
S & 32 & 16,4 \\
TS & 8 & 4,1 \\
STS & 1 & 0,5 \\
Total & 195 & 100,0 \\
\hline
\end{tabular}

Tabel 6 menunjukkan bahwa karyawan telah merasakan kepuasan kerja yang berhubungan dengan faktor promosi.

Tabel 7. Faktor Rekan Kerja

\begin{tabular}{ccc}
\hline & Frekuensi & Persen $(\%)$ \\
\hline SS & 118 & 60,5 \\
S & 54 & 27,7 \\
TS & 23 & 11,8 \\
STS & 0 & 0,0 \\
Total & 195 & 100,0 \\
\hline
\end{tabular}

Tabel 7 menunjukkan bahwa karyawan telah merasakan kepuasan kerja yang berhubungan dengan faktor rekan kerja.

Tabel 8. Faktor Gaji

\begin{tabular}{ccc}
\hline & Frekuensi & Persen $(\%)$ \\
\hline SS & 103 & 52,8 \\
S & 65 & 33,3 \\
TS & 27 & 13,8 \\
STS & 0 & 0,0 \\
Total & 195 & 100,0 \\
\hline
\end{tabular}

Tabel 8 menunjukkan bahwa karyawan telah merasakan kepuasan kerja yang berhubungan dengan faktor gaji.

\subsection{Analisis Regresi Linear}

Pengolahan data pada penelitian ini dilakukan dengan menggunakan program SPSS release 17. O for Windows. Dari hasil pengolahan data diperolah persamaan regresi sebagai berikut : $\mathrm{Y}=74,663+0,488 \mathrm{X}$. Persamaan regresi di atas menunjukkan sifat hubungan yang positif antara variabel persepsi tentang keadilan sistem kompensasi dengan variabel kepuasan kerja, hal ini berarti jika karyawan mempunyai persepsi bahwa keadilan kompensasi yang diterapkan oleh perusahaan semakin baik, maka kepuasan kerja yang yang dirasakan oleh karyawan juga meningkat. Dari persamaan regresi diketahui nilai $R$ Square sebesar 0,211 . ini menunjukkan bahwa variabel persepsi karyawan tentang keadilan kompensasi mempengaruhi variabel kepuasan kerja sebesar $21 \%$. Diperoleh nilai t-hitung sebesar 7,189 dan nilai t-tabel sebesar 1,9723. Karena nilai t-hitung lebih besar daripada nilai t-tabel, berarti variabel persepsi karyawan tentang keadilan kompensasi secara signifikan mempengaruhi variabel kepuasan kerja.

\subsection{Analisis Korelasi}

Analisa korelasi digunakan untuk mengetahui besarnya hubungan antara variabel independen $(\mathrm{X})$ terhadap variabel dependen (Y) (Ali, 2007). Perhitungan koefisien korelasi dilakukan dengan menggunakan teknik Pearson's Product Moment dengan bantuan program SPSS release 17. 0 for Windows. Hasil perhitungan koefisien korelasi antara variabel persepsi tentang keadilan sistem kompensasi dengan kepuasan kerja adalah sebesar 0,460, menunjukkan hubungan yang cukup erat. Arah hubungan positif berarti semakin besar persepsi karyawan tentang keadilan kompensasi akan membuat kepuasan kerja karyawan juga cenderung meningkat.

\section{KESIMPULAN DAN SARAN}

Berdasarkan hasil analisis pengolahan data dan pembahasan dalam penelitian ini, 
maka dapat diambil kesimpulan bahwa karyawan Perusahaan X mempunyai persepsi bahwa perusahaan telah menerapkan keadilan eksternal, keadilan internal dan keadilan individu dalam sistem kompensasi perusahaan. Karyawan Perusahaan X telah merasakan kepuasan kerja yang berhubungan dengan faktor pekerjaan, faktor atasan, faktor promosi, faktor rekan kerja, dan faktor gaji. Selain itu terdapat berdasarkan hasil analisis regresi linear, diketahui terdapat pengaruh yang signifikan antara persepsi karyawan terhadap keadilan kompensasi dengan kepuasan kerja. Dari hasil perhitungan koefisien korelasi antara variabel persepsi tentang keadilan sistem kompensasi dengan kepuasan kerja, dapat disimpulkan bahwa terdapat hubungan yang cukup erat dan menunjukkan arah hubungan yang positif, hal ini menunjukkan bahwa semakin bertambah baik persepsi karyawan tentang keadilan kompensasi akan membuat kepuasan kerja karyawan juga meningkat.

\section{DAFTAR PUSTAKA}

Ali, Sambas Muhidin dan Maman Abdurrahman, Analisis Korelasi, Regresi, dan Jalur dalam Penelitian, Pustaka Setia, Bandung, 2007.

Gibson, James L., Ivansevich, John M., Donnely, James H., Organizations: Behavior Structure Processes (10th ed). USA: McGraw-Hill companies, 2000 .

Hadi, Sutrisno, Metodologi Research. Penerbit Andi:Yogyakarta, 2004

Hasibuan, Malayu S. P, Manajemen Sumber Daya Manusia, PT. Bumi Aksara, Jakarta, 2013.

Marwansyah, Manajemen Sumber Daya Manusia. Alfabeta, Bandung, 2010.

Milkovich, Newman, Compensation. New York : McGraw-Hill, 2002.
Nawari, Analisis Regresi dengan MS Excel 2007 dan SPSS 17. PT Elex Media Komputindo Kompas Gramedia, Jakarta, 2010.

Simamora, Henry, Manajemen Sumber Daya Manusia. STIE YKPN Yogyakarta, 2004. 